\title{
The Present Situation Analysis and Empirical Study of Enterprise Accountant Foundation Work of Chinese Independent Brand Based on Factor Analysis Method
}

\author{
Yuxia Dong \\ School of Management, Langfang Teachers Education University, Langfang, China \\ d_ongyuxia@126.com
}

Keywords: factor analysis method; quantitative basis; technical support; network integration; matrix; comprehensive factor

\begin{abstract}
China's independent brand enterprises generally exist the problems of weak management foundation, internal accounting control issues which affect the economic benefits development growth even affect their survival of the enterprise. Basic accounting work will directly affect the reflection of whole enterprise's economic activities comprehensive, timely, objective. If the independent brand enterprises lack the awareness of the importance of basic accounting work that will lead to the chaos of basic accounting work, thus affect the accounting work and departmental management working in an orderly manner. Systematic analysis on the existing problems of accounting basic work by application of factor analysis method and the system's result solves the basis of the departments and provide a more rational, accurate reform decision support for managers.
\end{abstract}

\section{Introduction}

Nowadays, with the multi-polarization of the world and the trend of development of informatization of science and technology, economic globalization is one of the most significant features. Economic globalization affects enterprises of all countries deeply particularly developing countries. There are two characteristics of economic globalization to enterprises: one is scale which is not the traditional sense of the organization structure's enlargement[1]. With the development of new scientific and technological means, the virtual scale will become the latest explain of the enterprise scale. Another is efficiency, enterprise which have no efficiency as supporting must be " economy of scale "and will eventually be eliminated by the market[2].

Factor analysis is a multivariate statistical analysis method which perplexing numerous variables factors to several unrelated comprehensive factors. Its fundamental idea is divided the original variables into groups based on the correlation between the factors, such as the high correlation are in one group, low correlation are in another[3]. Each factor represents a basic structure called common factor which reflect one aspect or a dimension of the problem. Taking several common factor variance contribution rate as weights to construct a comprehensive evaluation function in order to simplify the full information between the original variable and treatment indicators effectively and achieve the purpose of dimension reduction and convenience for analysis.

Due to the characteristics of China's independent brand enterprises, there're problems of weak management foundation, internal accounting control issues which affect the economic benefits development growth even affect their survival of the enterprise[4]. Recently, social supervision system is not perfect in our country and many own brand enterprises decide on their own interests which lead to the distortion of enterprise accounting information. It can not reflect and disclosure the enterprise management and capital operation status truly, objective and clearly. So, strengthening and improving the accounting work has been crunch time[5]. This paper investigates independent brand enterprise accounting basic work status and analyzes the accounting problems existed in basic factor. It puts forward the solving strategies, theorize references and suggestions to strengthen accountant foundation job and Effective internal control.

\section{The status and development of China's independent brand enterprise's accounting basic work}

A. The status of China's independent brand enterprise

With the development of socialist market economy, people's living standard has been improved. The world is also aimed at the Chinese market and transnational group has a strong strength. 
Although more and more domestic enterprises had their own brand products, the lack of core technology and intellectual property lead to the added value of brands is still low. The domestic enterprises are under serious threat.

An own brand enterprises can sustain and healthy develop or not mainly depends on the following aspects[6,7]:

(1) Operating capacity

Operation ability is capital turnover and asset utilization efficiency ability of an enterprise. It reflects the enterprise management level and the assets ability. Management has a higher management level and the ability to use assets if the business ability is high.

In this case, the possibility of fraud on enterprise financial work is lower. Normal continuous operation ability is questionable if operating capacity is poor. It causes potential financial risk and management risk.

(2)Debt paying ability

Debt paying ability is a reflection of an enterprise whether it can repay the mature debt. Debt paying ability decides the enterprise survival and healthy progress. Debt management is a business strategy of some own brand enterprise. Debt management can not only make up for the inadequacy of company own reserves but also can realize profit by using the loan. However, if the debt ratio in the source of the enterprise funds is too large, the pressure of debt service will become larger. This will affect the normal growth and sustainable management. Therefore, when the enterprise debt paying ability is poor, it indicates that this enterprise's poor financial situation, weak debt security and stability, increasing possibility in violation of debt covenants and financial fraud in work motivation.

(3) Development capacity

The development ability of enterprises refers to the ability to expand their own potential ability through the expansion of scale to enterprise's survival. It includes enlarging enterprise scale and increasing owners' equity and profits. It can conclusion that the enterprise obtain funds to expand the business through profit or through other financing methods by analyze the development capacity of enterprise. If the business development capacity is good, the financial situation of enterprises is good and the ability to cope with risk and sustainable development is strong.

(4)Profit ability

Profitability is the enterprise's capital appreciation ability. It is the reflection of enterprise's income and level. Companies must be able to profit for the existence. Profit reflects the company's starting point and the final shrinkage. It is an important assure for investors to gain investment incomes. There are inflated profits behaviors which will affect the legitimacy and fairness of the enterprise accounting work because the management is facing punishment or financing pressure when the profitability is poor.

B. The main problems of our own brand enterprise's accounting basic work

Basic accounting work is generally refers to the collectively work of accounting and accounting management service. Mainly include hardware and software requirements: Accounting document format design, making, filling, audit, transfer, storage, account book format, settings, check, registration, checkout, types of accounting statements set, format design, preparation and audit requirements, accounting archives archiving requirements, retention, transfer procedures, destruction degree and computerized accounting to change and so on[8,9].

(1) Manager lacks of awareness

Some managers simply considered the basic accounting work as the collection, payment and the payment of wages. They have no awareness that the basic work of accounting have a great impact on enterprise's production and management. They are lack of awareness on accountants' professional learning and knowledge update which lead to accounting personnel can not keep up with the pace of basic work of accounting changes and each link of accounting work and management system requirements do not match.

(2) The problems of accounting personnel quality

In our own brand in the enterprise there generally exist these problems: undocumented appointment, lower quality, have no necessary expertise, lack of business knowledge updating learning.

Accountants are the basic link of the accounting basic work, so the quality of accounting personnel will be directly related to the basic work of accounting standardization and regularization. There exist a large proportion of accounting personnel who is undocumented appointment and they could not competent for accounting work. Even if some staff is documented appointment, there also 
has quite a part of them have low vocational level and the aging knowledge structure. Today, with the update of new financial regulations, accounting system, enterprise has put forward higher requirements to the timeliness, accuracy of business accounting data. The dull accounting has seriously affected the enterprise accounting information quality

(3) The distortion of accounting information

In some enterprise, because accountant's responsibility or occupation morality is not strong and for personal or corporate self-interest, they fabricate false accounting vouchers, accounting books, accounting statements, tax evasion in order to transfer assets to seek illegal income. These behaviors not only affected the normal operation of basic accounting work and accounting function seriously but also disturb the normal social and economic order.

(4)Internal control is not standard

This part contains: the audit procedures to original bill and reimbursement are not strictly; the signature of invoice are incomplete; can not meet the standardizing inner control system, can not carefully examine the original documents, false accounting vouchers, can not attach original evidence, abstract is not clear, the wrong amount, the mismatch between original documents and vouchers, increase or decrease the amount, consolidation of account; any changes in accounting content, can not check the general ledger and subsidiary ledger, can not inventory timely. All of this Lead to the inconsistent between general ledger and subsidiary ledger accounts and seriously incompatible between asset and real assets.

(5) Management monitoring is not enough

Recently, our companies generally have some phenomenon like the supervision of internal audit department or the supervision departments are not enough. The rules, daily supervision and inspection have no practical significance. Some companies even have unsupervised phenomenon

(6) Imperfect accounting system

Today,under the environment of accounting computerization all brand enterprise depend on computers.some accountant are ignore accounting basis of accounting work and they think about that as long as the reports set already it does not need to check the operation and have no need to check the report and analysis report. All of this wrong data causes the distorted reflection of the company .While in the tradition, most accountants were checked corresponding relationship between reports.

\section{Factor analysis method}

A. Factor analysis model

$X=\left(X_{1}, X_{2}, \cdots, X_{\rho}\right)^{\prime}$ is set as an observed random variable using $Y=\left(Y_{1}, Y_{2}, \cdots, Y_{\rho}\right)^{\prime}$ as $\mathrm{X}$ which

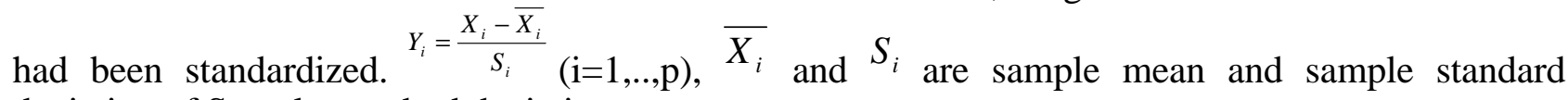
deviation of Sample standard deviation.

$F=\left(F_{1}, F_{2}, \cdots, F_{m}\right)^{\prime}(\mathrm{m}<\mathrm{p})$ is set as an unobserved random variable, $E(F)=0$, Covariance matrix $D(F)=I_{m}$.The $\varepsilon=\left(\varepsilon_{1}, \varepsilon_{2}, \cdots, \varepsilon_{\rho}\right)^{\prime}$ and F are entirely unrelated,

$E(\varepsilon)=0, D(\varepsilon)=\left[\begin{array}{lll}\sigma_{1}{ }^{2} & & \\ & \cdots & \\ & & \sigma_{p}{ }^{2}\end{array}\right]=\operatorname{diag}\left(\sigma_{1}{ }^{2}, \cdots, \sigma_{p}{ }^{2}\right)$

Assuming random vector $\mathrm{Y}$ can be expressed as the following model[10]:

$$
\left\{\begin{array}{c}
Y_{1}=a_{11} \mathrm{~F}_{1}+a_{12} F_{2}+\cdots+a_{1 m} F_{m}+\varepsilon_{1} \\
Y_{2}=a_{21} F_{1}+a_{22} F_{2}+\cdots+a_{2 m} F_{m}+\varepsilon_{2} \\
\cdots \\
Y_{\rho}=a_{\rho 1} F_{1}+a_{\rho 2} F_{2}+\cdots+a_{\rho m} F_{m}+\varepsilon_{\rho}
\end{array}\right.
$$

The above equation is called a factor model and short for: $Y=A F+\varepsilon$.The $F_{1}, F_{2}, \cdots, F_{m}$ in $F_{1}, F_{2}, \cdots, F_{m}$ are common factors. They are all variables shared by factors which reveal the correlation between variables. The $\varepsilon_{1}, \varepsilon_{2}, \cdots, \varepsilon_{\rho}$ in $\varepsilon=\left(\varepsilon_{1}, \varepsilon_{2}, \cdots, \varepsilon_{\rho}\right)^{\prime}$ are special factors. They're the special factor of each variable which indicate the part cannot be explained by the public factors. 
$A=\left(a_{i j}\right)_{p \times m}(\mathrm{~m}<\mathrm{p} ; \mathrm{i}=1, \ldots, \mathrm{p} ; \mathrm{j}=1, \ldots, \mathrm{m})$ been called factor loading matrix. ${ }_{i j}$ is the load of $Y_{i}$ in $F_{i}$.

The public factor has an effect on every component variable ${ }^{Y_{i}}$ of Y, but ${ }^{\varepsilon_{i}}$ only has an effect ${ }_{\text {on }} Y_{i} . S_{j}=\sum_{i=1}^{m} a_{i j}{ }^{2}$ is the contribution on public factor $F_{j}$ to Y. $S_{j}$ is the total variance of all variables provided by contribution rate which has been used to measure the relative importance of common factor.

Figure out public factor, if all public factors are not very prominent of the typical representative variables, it required factor rotation by an appropriate method for in order to find the new public factor which has better explain ability.

B. The basic steps of factor analysis

The basic steps of factor analysis includes the following aspects[11]:(1) Construction of the original data matrix;(2)The treatment of original data in the same direction;(3) Make these data standard in order to avoid the meaningless comparisonbetween the data because of the different dimension;(4) Calculate correlation coefficient matrix and the correlation coefficient matrix Eigen values and eigenvectors;(5) Extracting common factor according to the factor contribution rate by principal component analysis;(6) Calculate the maximum variance oblique rotation matrix, Eigen value, the cumulative contribution rate.

\section{Empirical analysis}

A. Sample selection and index variable

Taking our country independent brand enterprise development as samples, operating capacity F1, debt paying abilityF2, development capacity F3, profit ability F4 separately.Index variable is: manager lacks of awarenessX1; the problems of accounting personnel qualityX2 ;the distortion of accounting information X3;internal control are not standardX4 ;management monitoring is not enoughX5;imperfect accounting systemX6

B. Factor analysis

1) Choose the accounting index

First, staring from the financial index which reflects the enterprise's financial situation and operating performance, then, choosing 6 and coding for the original index of the Factor analysis. It can be seen in Tab 1 .

\begin{tabular}{|c|c|c|}
\hline character & name & number \\
\hline Operating capacity F1 & manager lacks of awareness & $\mathrm{X} 1$ \\
\hline \multirow{2}{*}{ Debt paying abilityF2 } & the problems of accounting personnel quality & $\mathrm{X} 2$ \\
\hline & the distortion of accounting information & X3 \\
\hline \multirow{2}{*}{ Development capacity F3 } & internal control is not standard & $\mathrm{X} 4$ \\
\hline & management monitoring is not enough & $\mathrm{X} 5$ \\
\hline Profit ability F4 & imperfect accounting system & X6 \\
\hline
\end{tabular}

2) Study of weather financial index is suitable for the factor analysis

Firstly, taking KMO test and Bartlett test of spheroid and judging the selected indicators of the suitability weather can used to factor analysis. For Tab.2, the observed value of Bartlett spheroid test is 4. 925E3, and the probability $\mathrm{P}$ value is Sig. $=0.000$,these data indicate the test result can do factor analysis. The result of KMO is 0 . 704 which means all variables have strong linear relationships. According to KOM measurement standard by Kaiser, the selected financial indicators can be used for factor analysis.

3) Extracting common factor

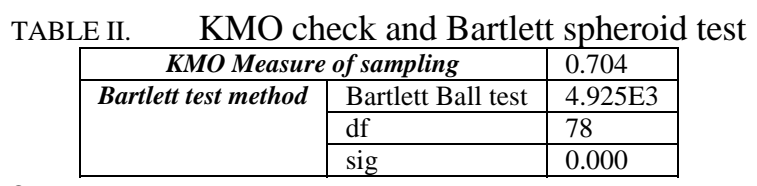

Using the principal component analysis method and extracting common factor from X1.Its characteristic root is more than 1 and contribution rate is $46.423 \%$ which has been named F1(for Tab.3).Do the same thing extractF2 from X2, X3;F3 from X4 X5 and F4 from X6. 
TABLE III. The cumulative contribution rate of Common factor

\begin{tabular}{|c|c|c|c|}
\hline Common factor & Eigen value & The variance contribution rate(\%) & The cumulative contribution rate(\%) \\
\hline F1 & 11.859 & 47.438 & 47.438 \\
\hline F2 & 7.362 & 29.446 & 76.884 \\
\hline F3 & 3.673 & 15.051 & 91.935 \\
\hline F4 & 12.262 & 56.561 & 61.878 \\
\hline
\end{tabular}

4) Calculate comprehensive factor score

This paper takes every variance contribution rate as weight to calculate the comprehensive score F. Its calculations are as follows: $\mathrm{F}=(47.483 * \mathrm{~F} 1+29.446 * \mathrm{~F} 2+15.051 * \mathrm{~F} 3+56.561 * \mathrm{~F} 4) / 61.878$.

TABLE IV. Comprehensive score and Order

\begin{tabular}{|l|l|l|l|ll|}
\hline factor & F1 & F2 & F3 & F4 & comprehensive score $\mathbf{F}$ \\
\hline $\boldsymbol{X} \mathbf{1}$ & 0.1192 & 0.1319 & 3.1356 & 2.342 & 0.617 \\
\hline $\boldsymbol{X} \mathbf{2}$ & 0.2957 & -0.4641 & 3.3065 & 2.876 & 0.545 \\
\hline $\boldsymbol{X} \mathbf{3}$ & 0.0267 & 0.4845 & 2.7250 & 1.673 & 0.613 \\
\hline $\boldsymbol{X} \mathbf{4}$ & 0.2034 & -0.1385 & 2.5473 & 1.087 & 0.477 \\
\hline $\boldsymbol{X} \mathbf{5}$ & 0.3232 & -0.4191 & 2.6138 & 1.976 & 0.460 \\
$\boldsymbol{X} \mathbf{6}$ & 0.2372 & -0.1325 & 2.3424 & 1.423 & 0.388 \\
\hline
\end{tabular}

It can calculate the comprehensive score by the four factor variables. The comprehensive score are ordered from highest priority to lowest. X1, X3, X2, X4, X5, X6 have an influence on China's independent brand enterprises. The order of importance is: manager lacks of awareness, the distortion of accounting information, the problems of accounting personnel quality, internal control is not standard, management monitoring is not enough, imperfect accounting system.

\section{Conclusion}

With the development of economy, the basic work of accounting in independent brand enterprises becomes more and more important. The basic accounting work is not only the premise of the enterprise accounting and financial management but also is an important foundation of business economic management. If accountants can not reflect enterprise basic work problems true, objective, complete and not try to correct, it will affect the understand and effectively use of accounting information for users and affect the operating results of business for many years. Application of factor analysis method to analyze the existing problems of the independent brand enterprise accounting basic work provides quantitative basis for the related departments and manager and play an important role in improving the operation and management, strengthening internal control, risk and other aspects.

\section{References}

[1] Peilin Gao,Guodong Dang. Administrative institution accountant foundation work status and Countermeasures . Western finance and accounting, 2011(11):61-64

[2] Guowen Liang. On the basis of accounting work present situation analysis and countermeasure .Chinese Health Economics, 2010(03):56-58

[3] Haoran Li. Study on enterprise finance transformation software -- the factor analysis method . Friends of accounting, 2012(11):22-24

[4] Lingyan Kong,Jing Duan. Based on the factor analysis of small and medium-sized enterprises performance evaluation [D].The new accounting, 2010(08):12-15

[5] Guowen Liang. On the basis of analysis on present situation of accounting work and countermeasure .Chinese Health Economics, 2009(03):34-39

[6] Jiafeng Yin. Strengthen accountant foundation job to ensure the quality of accounting information . China Science and technology information, 2011(03):59-60

[7] Zhenran Gao.Discussion on strengthening administrative institution accounting basic work Modern economic information, 2009(02):23-24

[8] Yuxiang Wang. Discussion on strengthening administrative institution accounting basic work. Modern economic information, 2011(7):35-39

[9] Lunzhi He,Lisheng Zeng. Economic system analysis.Social Science Literature Press, 2012:335. [10] Accounting Society of China. Accounting thesis option. China financial and Economic Publishing House, 2011(11):48-50

[11] Harter,J.K,Schmidt,F.L,Hayes,T.L.Business-Unit relationship between employee satisfaction,employee engagement and business outcomes.Journal of Applied Psychology,2011(2): 68-78. 